\title{
Informedness in Collaborative Networks through Active Information Provisioning
}

\author{
Heiko Thimm $^{1}$ and Karsten Boye Rasmussen ${ }^{2}$ \\ ${ }^{1}$ Pforzheim University, School of Engineering, Tiefenbronner Str. 65 \\ D-75015 Pforzheim, Germany \\ heiko.thimm@hs-pforzheim.de \\ ${ }^{2}$ University of Southern Denmark, Department Marketing and Management, Campusvej 55 \\ DK-5230 Odense, Denmark \\ kbr@sam.sdu.dk
}

\begin{abstract}
Successful collaboration in business networks calls for well-informed network participants. Members who know about the many aspects of the network are an effective vehicle to promote trust within the network, successfully resolve conflicts, and build a prospering collaboration climate. The importance of well-informed network participants has lead to our concept of network participant informedness which is derived from existing theories and concepts for firm informedness. Through a specialized IT based active information provisioning service it is possible to effectively obtain well informed network participants. A corresponding modeling framework and a rule based approach for the needed active system capabilities are presented.
\end{abstract}

Keywords: Collaborative Networks, Information Provisioning, Knowledge Management, Rule Based Information Management, Active Database Systems.

\section{Introduction}

Companies seek to improve their competitive position by collaborating with other companies in collaborative networks [2] that are expected to provide many potential benefits. The benefits include: reduction of costs due to economy of scale effects [8], access to new markets and extra resources [5], better access to partner expertise, faster collaboration forming [16], and creation of new business opportunities [6].

There exist different kinds of collaborative networks where the members collaborate in different areas such as knowledge sharing and joint product development [1]. It also can be observed in the networking practice that network members collaborate on the operational level [18]. That is, several members of a network jointly process business transactions such as inquiries and orders from the market. The joined customer order fulfillment processes of collaborative networks typically deliver a composite product or service for which the involved members contribute individual parts and services. The collaborative provisioning of composite products and services, can lead to crossorganizational processes with high complexity [14]. The subset of network members that participate in these processes for a specific business opportunity form a temporary 
alliance referred to as Virtual Enterprise (VE) [2]. A VE is terminated in a controlled way when the order or project resulting from the business opportunity is completed.

Successful collaboration in collaborative networks calls for network participants who are well-informed about the many aspects of the network [9]. Well-informed network participants can promote trust within the network, successfully resolve conflicts, and build a prospering collaboration climate.

Without an appropriate level of informedness, a network can be threatened by distrust between the participating members and distrust to the idea and outcome of the network. So far in the research literature on building and promoting trust in networks $[11,13]$ the role of informed network participants has not been studied extensively. The fact that modern companies are more often participating in business networks has only recently been addressed in theories on firm informedness [9]. Thus, there still exist numerous research questions in this particular area of collaborative networks. In our work we are addressing some of these issues with the goal to define a foundation for an active information provisioning service in collaborative networks. We in the current stage of our research consider especially the type of collaborative networks where the completion of customer orders implies joint order fulfillment processes by a subset of network members. For example, the members being selected to work together in a VE fulfill complementary parts of the order such as production steps. As a further characteristic of the focused network type we assume that the network is managed by a central management instance such as a human moderator [19]. Our proposed service is not intended to substitute such a moderator. Instead it is the objective of the service to free the moderator from routine information dissemination tasks. The example cases presented in the article will illustrate this specific type of collaborative networks.

By active information provisioning we mean a service that automates a continuous and asynchronous delivery of information about the many networking aspects according to the individual network participant's needs. The automated information provisioning through an IT support service will reduce the influence of time constraints on the informedness of network members. We propose the concept of network participant informedness as a theoretical basis for such a service as a novel addition to our earlier work on active information provisioning in collaborative networks [20]. In this article we will discuss central aspects and possible generic solutions for the service. This includes a specialized modeling framework for information provisioning and an approach for the needed active system capabilities. We propose the use of an EventCondition-Action rule formalism [15]. Through this approach it is possible to couple the active provisioning of tailored information to temporal events and conditions that refer to network indicators and states of business processes that are simultaneously executed in the network.

Following this introduction we introduce the concept of network participant informedness in section two. Section three and four give an overview of our modeling framework and our rule based approach for active provisioning. An outlook for our future work and concluding remarks are contained in section five. 


\section{Firm Informedness in Collaborative Networks}

It is a generally accepted fact that information is a source of competitive advantage for firms [3]. For example, the use of information with or without IT can lead to both improved business capabilities but also to new business capabilities [10, 12]. By improving the availability of information a possibility is created for firms and customers to achieve a new level of informedness. Clemons [4] defines consumer informedness as the degree to which consumers know the products or services, and their precise attributes and prices that are available in the market. Kauffman's firm informedness theory [9] extends this consumer informedness theory to include both consumer informedness and firm informedness.

On the grounds of these theories we are suggesting the concept of network participant informedness. In general, we refer by this concept to firms as members of a collaborative network and especially their knowledge about the many aspects of the network. Similar to the informedness theory of Kauffman [9] we first of all require informed network participants to know about resources, competences, and the value of other participants in co-production. The knowledge about the participants' value in co-production concerns both shared and private high quality information about the network strategy, the current network status, and also the business processes that are cooperatively executed within the network. In addition to knowing isolated details of these information categories well-informed network participants also understand the semantic relations between the different information items. That is, they have a broad understanding of the structure of the network and its business capabilities.

A high level of network participant informedness can be achieved with and without IT. If information availability for network participants is not based on IT still a high level of network participant informedness can occur. The intrinsic motivation of the participants to be well-informed about what is going on in the network can lead to an appropriate level of informedness. However, aiming at an appropriate level of informedness without use of IT support will usually require substantial time efforts and lead to high information acquisition cost.

For that reason, our research targets a flexible information provisioning service to automate information provisioning to the network participants. The system will be presenting tailored content about the above mentioned network aspects in the form of reports frequently delivered by the service. User-defined provisioning schemes will determine at what exact instances of time reports are to be delivered.

Table 1 contains an illustration of a sample report prepared for a network member Metal Gurus. This report informs about an ongoing inquiry handling business process for a customer Volcano ships. The details of this sample report are as follows. Information specific to the inquiry received is contained in row 1 . Row 2 describes the fulfillment steps (called request elements denoted by $R E_{u}(<a$ textual description $>$ ), $u=1, \ldots, k$ needed to complete a corresponding order. Row 3 contains the VE (i.e. Virtual Enterprise) in charge of the inquiry with details about the corresponding request elements and the assigned network members denoted by $M_{v}, v=1, \ldots, l$. Information about the quotation issued and the corresponding response received from the inquiring shipyard are contained in row 4 and 5, respectively. Row 6 provides information about the resulting order received by the network. 
Table 1. Sample report informing about an ongoing inquiry handling process

\begin{tabular}{|c|c|c|}
\hline \multicolumn{3}{|c|}{ Report-ID: 161109-091624, Generation Date: 2009-11-16, Prepared for: Metal Gurus } \\
\hline & Caption & Content \\
\hline 1 & $\begin{array}{l}\text { New inquiry } \\
\text { received: }\end{array}$ & $\begin{array}{l}\text { Inquiry ID: 210409-1654-59, Date received: } 2009-04-21 \text {, Inquiring } \\
\text { company: Volcano Ships, Inquiry description: } 400 \text { seats (Ocean Con- } \\
\text { venience) with final assembly at customer's site, Demanded delivery: } \\
2009-12-30\end{array}$ \\
\hline 2 & $\begin{array}{l}\text { Request ele- } \\
\text { ments: }\end{array}$ & $\begin{array}{l}R E_{1} \text { (provision of metal seat frame), } R E_{2} \text { (provision of seat upholster- } \\
\text { ies), } R E_{3} \text { (provision of circuit systems), } R E_{4} \text { (provision of monitors), } \\
R E_{5} \text { (provision of harnesses), } R E_{6} \text { (final assembly of seat) }\end{array}$ \\
\hline 3 & $\begin{array}{l}\text { VE in charge } \\
\text { of inquiry: }\end{array}$ & $R E_{1}\left[M_{3}\right], R E_{2}\left[M_{6}\right], R E_{3}\left[M_{9}\right], R E_{4}\left[M_{9}\right], R E_{5}\left[M_{13}\right], R E_{6}\left[M_{7}\right]$ \\
\hline 4 & $\begin{array}{l}\text { Quotation is- } \\
\text { sued to cus- } \\
\text { tomer: }\end{array}$ & $\begin{array}{l}\text { Quote ID: } 260409-1332-16 \text {, Date issued: } 2009-04-26 \text {, Quote Descrip- } \\
\text { tion: Offer for } 400 \text { standard seats (Ocean Convenience) with final as- } \\
\text { sembly at customer's site, Offered Price: } 880 \mathrm{~K} €\end{array}$ \\
\hline 5 & $\begin{array}{l}\text { Quotation re- } \\
\text { sult received: }\end{array}$ & $\begin{array}{l}\text { Quote ID: } 260409-1332-16 \text {, Date received: } 2009-05-02 \text {, Quote result: } \\
\text { positive, Response of customer: Offer accepted without changes; will } \\
\text { sign contract }\end{array}$ \\
\hline 6 & $\begin{array}{l}\text { Order re- } \\
\text { ceived: }\end{array}$ & $\begin{array}{l}\text { Order ID: 080509-0918-34, Date received: 2009-05-08, Quote ID: } \\
\text { 260409-1332-16 }\end{array}$ \\
\hline
\end{tabular}

\section{Modeling Framework for Information Provisioning}

In this section we propose a modeling framework for flexible information provisioning in collaborative networks. Our framework consists of an extensible set of predefined information object types that belong to the information object categories State Object Type and Process Object Type.

In general State Object Types (SOT) correspond to network indicators that refer to network state information. Table 2 contains the skeletons of four examples. Each predefined object type is given an identifying and unique object type name such as Inquiries Received SOT. It is first explained in Table 2 what specific indicators the individual objects of the given types represent. Then, the base content and complementary content of each object type is described. These two concepts are similar to properties in object-oriented modeling [17]. The base content specifies the information content provided by the object by default. From a semantic point of view the base content primarily refers to aggregated information about the entire network. For example, objects of type Inquiries Received SOT by default provide the number of external inquiries received by the network together with related statistical information. The complementary content corresponds to further complementary information from the analytical context of the object's base content. In contrast to the base content, the complementary content provides information that is specific to the own company. For example, while the base content of objects of type Inquiries Received SOT will provide the number of inquiries received by the entire network, the complementary content will provide the number of received inquiries where the own company has been a supplier. 
Table 2. Skeletons of four sample State Object Types

\begin{tabular}{|l|l|l|l|}
\hline $\begin{array}{l}\text { Inquiries Re- } \\
\text { ceived SOT }\end{array}$ & $\begin{array}{l}\text { Quotations } \\
\text { Given SOT }\end{array}$ & $\begin{array}{l}\text { Orders Re- } \\
\text { ceived SOT }\end{array}$ & $\begin{array}{l}\text { VES Formed } \\
\text { SOT }\end{array}$ \\
\hline Individual object represents the set of ... & formed VEs \\
\hline $\begin{array}{l}\text { external inquiries } \\
\text { received }\end{array}$ & $\begin{array}{l}\text { quotations given to } \\
\text { customers }\end{array}$ & received orders \\
\hline Base content concerns number(s) and detailed statistical information about ... \\
\hline $\begin{array}{l}\text { inquiries received by } \\
\text { network }\end{array}$ & $\begin{array}{l}\text { quotations issued to } \\
\text { customers }\end{array}$ & orders received & VEs formed \\
\hline Complementary content concerns number(s) and detailed statistical information about ... \\
\hline $\begin{array}{l}\text { inquiries where own } \\
\text { company is de- } \\
\text { manded as a supplier }\end{array}$ & $\begin{array}{l}\text { quotations where } \\
\text { own company is } \\
\text { considered as a } \\
\text { supplier }\end{array}$ & $\begin{array}{l}\text { orders where own } \\
\text { company is consi- } \\
\text { dered as a supplier }\end{array}$ & $\begin{array}{l}\text { formed VEs with } \\
\text { participation by } \\
\text { own company }\end{array}$ \\
\hline
\end{tabular}

Table 3. Skeletons of two sample Process Object Types

\begin{tabular}{|c|c|}
\hline Inquiry Handling POT & Order Fulfillment POT \\
\hline \multicolumn{2}{|l|}{ Individual object represents a concrete ... } \\
\hline inquiry handling process & order fulfillment process \\
\hline \multicolumn{2}{|c|}{ Processing states and corresponding base content (BC) and complementary content (CC) } \\
\hline 1. Inquiry Received & 1. Order Received \\
\hline \multirow{3}{*}{$\begin{array}{l}\text { Who issued inquiry? (BC) } \\
\text { What product/service is demanded? (BC) } \\
\text { Has the own company been requested as suppli- } \\
\text { er? (CC) }\end{array}$} & To what offer is referred? (BC) \\
\hline & 2. Suborders Issued \\
\hline & \multirow{3}{*}{$\begin{array}{l}\text { Which suborders have been issued? } \\
\text { (BC) } \\
\text { What are the details of the suborder } \\
\text { issued to own company? (CC) }\end{array}$} \\
\hline 2. Inquiry Decomposed & \\
\hline What are the elements of the inquiry? (BC) & \\
\hline 3. VE Configured & 3. Suborders Completed \\
\hline $\begin{array}{l}\text { Which partners are assigned to the inquiry? (BC) } \\
\text { What are the VE configuration details of the own } \\
\text { company? (CC) }\end{array}$ & \multirow{2}{*}{$\begin{array}{l}\text { When were all suborders completed? } \\
\text { (BC) } \\
\text { What are the completion details of the } \\
\text { suborder of the own company? (CC) }\end{array}$} \\
\hline 4. Quotation Issued & \\
\hline \multirow[t]{2}{*}{$\ldots$} & 4. Order Completed \\
\hline & \\
\hline
\end{tabular}

In general Process Object Types (POT) correspond to information about the execution of business processes within the network such as inquiry handling, order fulfillment, and marketing campaign planning. The individual objects of these types can be regarded as proxy objects that represent real world business processes executed within the network. Table 3 contains the skeletons of two examples which have the unique object type names Inquiry Handling POT and Order Fulfillment POT. Each type's sequence of potential processing states which are of interest to network members is specified. Note that in Table 3 the state sequences and state descriptions are not fully defined. The description of each state consists of a state number and a unique state name such as 1 . Inquiry Received. Furthermore, a set of questions is given for each state. These questions describe the specific information items available in the given and also all following states. The information items that refer to the business process 
from the global view of the entire network are referred to as the base content of the object which is specified by the acronym BC in the state descriptions of Table 3 . The company specific process information items are referred as complementary content of the object (specified by CC).

Based on our modeling framework it is possible to create and maintain an appropriate level of network participant informedness by a frequent information provisioning. The information provisioning operations can be described in terms of the information objects to be retrieved and the further information processing operations required to prepare informative reports as described above. The preparations can consist of calculations performed with the retrieved information items and also the completion of layout and formatting operations. Note, however, since we aim on a reoccurring provisioning of similar information items, a generic description of the relevant information objects and preparation operations is needed. This approach is similar to the popular generic forms of information systems. We refer to these generic descriptions in our framework by report templates.

\section{Rule Based Information Provisioning}

Active information provisioning in our research means that if certain expected events occur information is provided to users (subscribers) based on a push rather than a pull mechanism. Not only what information is to be prepared but also when the information preparation has to be performed should be as much as possible under control of the users. For this reason we support user defined information provisioning schemes which are associated with corresponding report templates.

In the following we describe our rule based approach for provisioning schemes. The approach is based on the ECA model which is the most popular model for the specification of rules in active database systems [15]. The ECA model defines a rule to consist of three parts, event, condition, and action. The semantic is that whenever the event happens, the condition is evaluated, and if satisfied then the action is taken.

We first of all assume a database that stores general information about the network and its members. The user defined report templates are also stored in this database. Furthermore, the database stores information about the current status of the network represented as a corresponding set of SOT objects. Information about currently executing and also already completed business processes in the network are administered in the database, too. This process information is represented as POT objects. Assuming the use of relational database technology the data are stored in flat tables for every defined SOT and POT type. Another separate table is kept for each of the defined set of a process's states in order to administer process state information.

Given the above outlined database the three components of ECA rules can be generally described as in Table 4. We divide the set of relevant events into four sub-sets. The first subset of events refers to value changes of network indicators. The second subset refers to the registration of new business processes and the third subset reflects state changes of business processes. The fourth subset of events is different from the previous events. This subset represents time controlled events where the level of time granularity here is restricted to a calendar day. In the condition part of our rules it is referred to values of network indicators and values related to business processes. In 
particular, conditions are described that imply the usual comparison operations of numeric values. The conditions can be very short and only consist of a single comparison operation. But it is also possible to specify complex condition statements by combining several single comparison operations by the logical binary operators. This approach for our conditions is described in Table 4 in the popular EBNF notation [7]. As actions of our rules we consider the orchestration of information reports according to user defined report templates and the provisioning of the reports to the corresponding users.

Table 4. Using the ECA rule model for Active Information Provisioning

\begin{tabular}{|c|c|c|c|c|}
\hline $\mathrm{E}$ & & & & \\
\hline C & \multicolumn{4}{|c|}{$\begin{array}{l}\text { Given the database state at time } t_{i} \text { referred to by } D B_{t_{i}} \text { and given any pair of } \\
\text { object items } O I_{l}, O I_{k} \in D B_{t_{i}} \text { which are data values of SOT objects or POT } \\
\text { objects, then a condition cond is cond }=\left(\text { cond }_{\text {single }} \mid \text { cond } d_{\text {composite }}\right) \text { with } \\
\text { cond } d_{\text {single }}=O I_{l}(=|\neq| \leq \mid \geq)\left(O I_{k} \mid C\right) \text { with } C \in \mathbb{R}_{0} \text { and } \\
\text { cond } \text { composite }_{\text {single }}=\text { cond }_{\text {single }}\{(\Lambda \mid \mathrm{V}) \text { cond }\}_{1}\end{array}$} \\
\hline & \multicolumn{4}{|c|}{$\begin{array}{l}\text { Generation of individual report according to a referred user-defined report } \\
\text { template and provision to user }\end{array}$} \\
\hline
\end{tabular}

\section{Outlook and Conclusions}

Based on the concepts introduced in this paper a first "light-weight" prototype for an active information provision service has been specified. Through experiments with the prototype we expect to gain further insights especially concerning the active system capabilities and the modeling framework. Among others, the results of the experiments will lead to both an extension and refinement of the predefined object types. Through the prototype we will also obtain requirements for the functionality that the service needs to offer to the various user types. For example, this includes functionality for the extension of the predefined object types by the system administrator. This also includes functionality for the specification of report templates and provisioning schemes by the users of the service. Through manual data entry activities our prototype is provided with information about executing business processes. We will extend this approach by a corresponding data interface so that process information can be exchanged with a business process monitoring environment.

For our proposed service approach several implementation barriers are to be considered. There is first of all the requirement that the relevant information objects and processes of the network need to be defined, analyzed, and mapped to our modeling framework. This can require a substantial amount of work and especially group negotiations and decision processes in order to obtain globally agreed process definitions. Furthermore, the technical integration of the various pre-existing systems with our service can lead to complicated integration problems due to the expected heterogeneity of the involved systems. 


\section{References}

1. Braha, D., Bar-Yam, Y.: Information flow structure in large-scale product development organizational networks. J. of Information Technology 19(4), 244-253 (2004)

2. Camarinha-Matos, L.M., Afsarmanesh, H.: Collaborative networks: a new scientific discipline. J. of Intelligent Manufacturing 16, 439-452 (2005)

3. Clemons, E.K., Row, M.C.: Sustaining IT advantage: the role of structural differences. MIS Quarterly 15(3), 275-292 (1991)

4. Clemons, E.K.: How information changes consumer behavior and consumer behavior determines corporate strategy. J. Mgmt. Information Systems 25(2), 13-40 (2008)

5. Davidow, W.H., Malone, M.S.: The Virtual Corporation. Harper Business, New York (1993)

6. van Heck, E., Vervest, P.: Smart business networks: how the network wins. CACM 50(6), 28-37 (2007)

7. ISO/IEC 14977: ISO Standard for the EBNF (1996)

8. Jarillo, J.C.: Strategic Networks: Creating the Borderless Organization. ButterworthHeinemann, Oxford (1993)

9. Kauffman, R., Li, T., van Heck, E.: A Theory of Informedness and Business Network CoProduction. In: Proceedings Hawaii Int. Conf. System Sciences, p. 1-10 (2010)

10. Kohli, R., Grover, V.: Business value of IT: an essay for expanding research directions to keep up with the times. J. Association Information Systems 9(1), 23-29 (2008)

11. Kumar, K., Diesel, H.G.: Sustainable Collaboration: Managing Conflict and Cooperation in Interorganizational Systems. MIS Quarterly 20(3), 279-300 (1996)

12. Li, T.: Informedness and Customer-Centric Revenue Management. Thesis, Erasmus Univ., Netherlands (2009)

13. Msanjila, S.S., Afsarmanesh, A.: A Multi-Model Approach to Analyze Inter-organizational Trust. In: Collaborative Networks reference modeling, pp. 195-216. Springer, New York (2008)

14. Mulder, W., Meijer, G.T.: Distributed Information Services Supporting Collaborative Network Management. In: Network-Centric Collaboration and Supporting Frameworks, pp. 491-498. Springer, Boston (2006)

15. Paton, N., Diaz, O.: Active Database Systems. ACM Computing Surveys 31(1) (1999)

16. Österle, H., Fleisch, E., Alt, R.: Business Networking - Shaping Collaboration Between Enterprises. Springer, Berlin (2001)

17. Rumbaugh, J., et al.: Object-Oriented Modeling and Design. Prentice Hall, Englewood Cliffs (1991)

18. Saxena, K.B.: Business Process Management in a Smart Business Network Environment. In: Vervest, et al. (eds.) The Network Experience, pp. 69-81. Springer, Berlin (2009)

19. Thimm, H., Rasmussen, K.B.: An Information Support Service for Moderators of SME Company Networks. Management Research News 32(9), 846-857 (2009)

20. Thimm, H., Rasmussen, K.B.: An Active Information Provisioning Service for Collaborative Networks. In: Proceedings IADIS Int. Conf. on e-Society, Porto, pp. 282-290 (2010) 